\title{
Seismic demand on light acceleration-sensitive nonstructural components in European reinforced concrete buildings
}

\author{
Petrone C., Magliulo G. *, Manfredi G.
}

Department of Structures for Engineering and Architecture, University of Naples Federico II, Naples, Italy

\begin{abstract}
In this paper a parametric study is conducted in order to evaluate the seismic demand on light acceleration-sensitive nonstructural components caused by frequent earthquakes. The study is motivated by the inconsistent approach of current building codes to the design of nonstructural components; moreover, the extensive nonstructural damage recorded after recent low intensity earthquakes also encouraged such a study.

A set of reinforced concrete frame structures with different number of stories, i.e. 1 to 10 stories, are selected and designed according to Eurocode 8. The structures are subjected to a set of frequent earthquakes, i.e. 63\% probability of exceedance in 50 years. Dynamic nonlinear analyses are performed on the reference structures in order to assess the accuracy of the equations to predict seismic forces acting on nonstructural components and systems in Eurocode. It is concluded that the Eurocode equations underestimate the acceleration demand on nonstructural components for a wide range of periods, especially in the vicinity of the higher mode periods of vibration of the reference structures; for periods sufficiently larger than the fundamental period of the structure, instead, the Eurocode formulation gives a good approximation of the floor spectra. Finally, a novel formulation is proposed for an easy implementation in future building codes based on the actual Eurocode provisions. The proposed formulation gives a good estimation of the floor spectral accelerations and is able to envelope the floor spectral peaks due to the higher modes.
\end{abstract}

\section{KEYWORDS}

Floor spectra, floor acceleration, nonstructural components, building codes, seismic demand.

\footnotetext{
* Correspondence to: Prof. G. Magliulo, Department of Structures for Engineering and Architecture, via Claudio 21, 80125 Naples, Italy. E-mail: gmagliul@unina.it. Tel.: +390817683656. Fax: +390817685921.
} 


\section{INTRODUCTION}

Nonstructural components are all the systems and components attached to the floors and walls of a building that are not part of the main structural system [1]. They can be classified in different categories according to the structural response parameter that is better correlated to their damage [2]. Acceleration-sensitive components, e.g. parapets and suspended ceilings, can be distinguished from (relative) displacement-sensitive components, e.g. windows and elevator cabins. The majority of the components can be classified as both acceleration- and displacement-sensitive components [3], such as fire sprinklers and heavy infill walls. For this reason consideration of both forces and displacements is prudent for all nonstructural systems. The seismic performance of nonstructural components is nowadays recognized to be a key issue in the framework of the performance-based earthquake engineering.

- The failure of nonstructural components can cause injuries or deaths; for instance, the failure of cladding panels in precast buildings was the main cause of fatalities in the 2012 Emilia earthquake (Northern Italy) [4].

- The nonstructural components generally exhibit damage for low seismic demand levels. Their damage can impair the functioning of the buildings. This issue is vital in emergency facilities, such as hospitals or fire stations, that should remain operative soon after the seismic event. The seismic performance of nonstructural components is especially important in frequent, and less intense, earthquakes, in which their damage can cause the inoperability of several buildings. For instance, a $4.9 \mathrm{M}_{\mathrm{w}}$ earthquake, that struck the northern part of the Campania region in Italy on 29 December 2013 caused many building evacuations mainly due to nonstructural component damage, such as internal partitions and infill walls (Figure 1).

- The cost connected to nonstructural components represents the largest portion of a commercial building construction [2]; the economic loss due to the failure of nonstructural components may exceed the replacement cost of the building, in case the loss of inventory and the downtime loss caused by nonstructural components are taken into account [5].

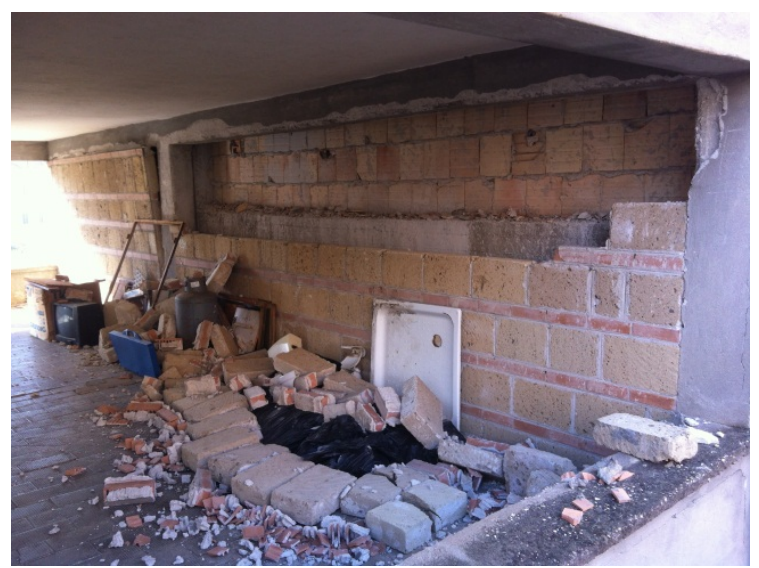

(a)

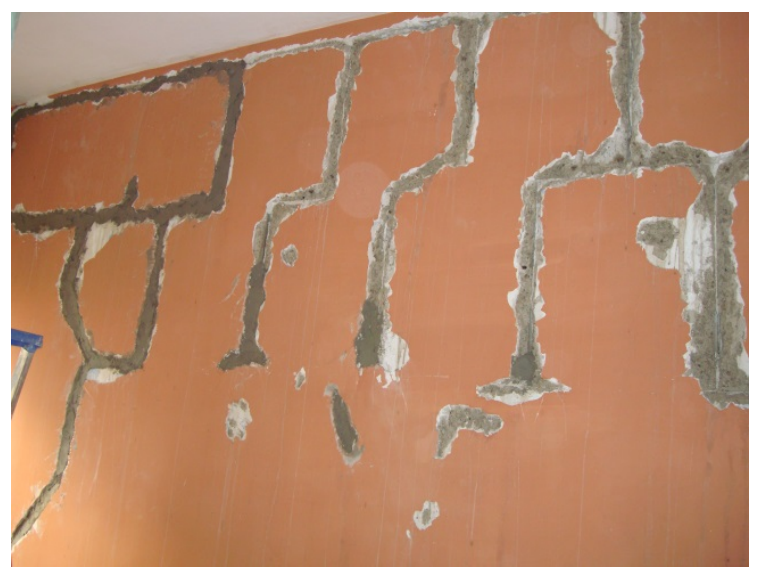

(b)

Figure 1. Damage to (a) infill walls and to (b) internal partition after a 4.9 $\mathrm{M}_{\mathrm{w}}$ Italian earthquake.

It is therefore widely recognized that the nonstructural components should be carefully designed for seismic actions. Many research studies were conducted with the purpose of assessing the seismic demand on nonstructural components, especially the accelerationsensitive ones, as well as the seismic capacity of such components [6, 7]. First studies on the evaluation of the seismic demand on acceleration-sensitive components, i.e. floor response spectra, were performed by Lin and Mahin [8] and Sewell et al. [9, 10]; they investigated the influence of the nonlinear behavior of the primary structure on the floor response spectra. 
More recent studies are performed on the same topic [11, 12] both for a SDOF and MDOF primary structures; in the latter study, the floor spectra of a multi-story frame respecting capacity design requirements are also investigated.

Rodriguez et al. [13] evaluated the earthquake-induced floor horizontal accelerations in cantilever wall buildings built with rigid diaphragms. They described several methods prescribed by design standards and proposed a new method for the evaluation of the design horizontal forces. Singh et al. [14, 15] proposed two methods for calculating the seismic design forces for flexible and rigid nonstructural components. The methods exploited the dynamic characteristics of the component, expressed in terms of fundamental periods and damping ratios, and of the supporting structure to calculate the seismic demand on nonstructural components. The validity of such methods was verified by comparing their floor response spectra with the ones obtained for an ensemble of earthquakes exciting several buildings with different numbers of stories. Fathali and Lizundia [16] analyzed the recorded ground and floor motion data collected in the framework of the California Strong Motion Instrumentation Program (CSMIP). They proposed a nonlinear relationship between the peak floor acceleration (PFA) and the corresponding height of the component in the building. Moreover, they proposed a three-segment floor spectrum composed of a linear rise at short periods, a flat segment at medium-range periods and a nonlinear decaying segment at longer periods. Sullivan et al. [17] addressed the shortcomings of the Eurocode 8 formulation for the definition of floor response spectra both in an 8-story and in a 20-story cantilever RC wall structure. They also proposed calibrated equations to predict floor spectra on single degree of freedom supporting structures. They finally encouraged further researches on multi-degree of freedom supporting structures.

In this paper a parametric study is conducted in order to evaluate the seismic demand on light acceleration-sensitive nonstructural components caused by frequent earthquakes. The study is motivated by the inconsistent approach of the current European and Italian building codes, as detailed in the Section 2. The above mentioned nonstructural damage exhibited after low intensity earthquakes also encouraged such a study. Moreover, very limited studies concerning the Eurocode 8 [18] formulation for the evaluation of the floor spectral acceleration were performed, according to which the seismic demand on a given nonstructural component is evaluated. Past studies were usually focused either on simple structures, e.g. SDOF structures, or on steel and wall buildings.

A set of RC frame structures are selected and designed according to Eurocode 8. Dynamic nonlinear analyses are performed on the reference structures in order to validate the Eurocode formulation. The floor response spectra are compared to the Eurocode 8 formulation; some considerations on the peak floor acceleration and on the component amplification are also included. Finally, a novel approach for the definition of the design floor response spectra is proposed for an easy implementation in future building codes.

\section{MOTIVATIONS: WHY TO INVESTIGATE FLOOR SPECTRA CAUSED BY FREQUENT EARTHQUAKES?}

Current building codes, such as Eurocode 8 (EC8) [18] and Italian Building Code (NTC 08) [19], provide that the ultimate limit states should not to be exceeded for a rare earthquake, e.g. 475-year return period earthquakes for ordinary buildings, and the damage/serviceability limit states are not to be overcome for a frequent earthquake, e.g. 50-year return period earthquakes for ordinary buildings, according to the approach included in [20]. The ultimate limit states concern the safety of the people and of the structure, whereas the serviceability limit states concern the functioning of the structure.

The Italian Building Code accurately defines the two limit states considered during the design phase as a function of the damage that occurs both at structural and nonstructural components. 
The ultimate limit state achievement implies that nonstructural components are already failed and the structural components are damaged, but the structure still has a safety margin with respect to the collapse. The damage limit state, instead, is attained in case structural components, nonstructural components and contents exhibit a minor damage level that does not threaten the life safety and does not reduce the safety of the building. The structural performance objectives can be deduced from these limit state definitions: both nonstructural and structural components should not be damaged for a frequent seismic event, whereas for a rare event the nonstructural components can collapse and the structural components can exhibit damage without implying the failure of the structure.

The "damage limitation requirement" is deemed to be satisfied by just limiting the structural interstorey drifts for frequent earthquakes; the limitation implies that displacement-sensitive nonstructural components are not damaged in case a frequent earthquake occurs. Both EC8 and NTC 08 provide that acceleration-sensitive nonstructural components, instead, are designed in order to withstand the seismic demand caused by a rare earthquake, e.g. a 475year return period event for ordinary buildings. This approach is inconsistent: indeed, while it is implicitly accepted that displacement-sensitive nonstructural components may collapse for a rare earthquake, acceleration-sensitive components should not collapse for such an intense motion.

It is definitely important to verify that nonstructural components do not exhibit major damage for a frequent earthquake, considering the limit state definitions/performance objectives mentioned above. Instead, it is questionable to verify such components against a rare earthquake; it does not make sense to verify their safety, while, according to the definition of the ultimate limit state, it is accepted that they can collapse for a rare earthquake. The verification for a rare earthquake could be conducted only for nonstructural components that can threaten the life safety in case of failure. Therefore, it seems reasonable to design acceleration-sensitive nonstructural components in ordinary buildings according to frequent earthquakes. For this reason, the research study aims at evaluating the seismic demand on acceleration-sensitive nonstructural components caused by frequent earthquakes. It should be underlined that the following considerations are limited to ordinary buildings, i.e. Importance Class II buildings according to EC8. Indeed, nonstructural components inserted in strategic facilities, such as hospitals, must remain operational even for rare earthquakes [21].

An important advantage is connected to the study of the seismic demand on nonstructural components due to frequent earthquakes. Indeed, floor response spectra obtained from dynamic analysis for rare earthquakes show that the nonstructural components acceleration demand depends on the ductility demand level of the primary structure [22, 23]. However, the ductility demand is not easily predictable during the design phase, because the structural overstrength reduces the ductility demand compared to the one assumed during the design phase [24, 25]. For frequent earthquakes it can be assumed that the primary structure does not exhibit large excursions in plastic range. In this case it is not necessary to rigorously assess the level of ductility and the structural overstrength for evaluating the acceleration demand on nonstructural components.

Finally, different studies available in literature $[14,17]$ evidenced that rare earthquakes induce large floor accelerations in buildings, that are typically underestimated by the code formulas. The question arises how to design a nonstructural component in order to withstand such a large acceleration demand, that may be larger than 10 - 20 times the peak ground acceleration [14]. 


\section{METHODOLOGY}

\subsection{Design of the reference structures}

Five multi-story RC frame structures are designed according to Eurocode 8 (EC8) [18] provisions. These reference structures are characterized by a different number of stories, i.e. one, two, three, five and ten stories, and by a $3 \mathrm{~m}$ interstorey height and two $5 \mathrm{~m}$ wide bays in each direction. RC frame structure is a very common structural typology in Italy and Europe, as pointed out by different literature studies [26, 27].

Modal response spectrum analyses are performed considering a $0.25 \mathrm{~g}$ design ground acceleration on stiff soil $\mathrm{ag}_{\mathrm{g}}$. The horizontal elastic response spectrum is defined referring to a $5 \%$ damping ratio and a 1.2 soil factor, i.e. soil type B. The seismic design meets the ductility class "high" (DCH) requirements: the assumed behavior factor is 4.95 for the one-story frame and 5.85 for the multi-story frames. According to EC8, a halved moment of inertia is considered for the primary elements, in order to take into account the effect of cracking. The design fundamental periods of the reference structures are listed in Figure 2.

The mass is lumped at each story considering the actual column and beam cross sections. The dead weight of the slab is evaluated according to the typical RC slab dimensions used in European constructions. The mass per square meter ranges from $0.87 \mathrm{t} / \mathrm{m}^{2}$ at the $1^{\text {st }}$ floor of the 1 -story structure to $1.39 \mathrm{t} / \mathrm{m}^{2}$ at the $1^{\text {st }}$ floor of the 10 -story structure.

The dimensions of the column cross sections are strongly influenced by the restricted value of normalized design axial force; indeed, the average compressive stress over the concrete compression strength must not exceed 0.55 . The limitation is especially valid for tall structures.

\subsection{Modeling}

Dynamic analyses are carried out for a set of seven earthquake records, on both linear and nonlinear models. Both linear and nonlinear analyses are performed on the central 2D frame of the reference structures (Figure 2). RC slabs and rigid diaphragms are considered for each floor; a third of the seismic mass is assigned to a master joint at each floor. Analyses are performed using the OpenSees program [28].

The study is focused on light nonstructural components. Hence, dynamic nonstructural component-structure interaction effects can be neglected. 
1-story structure - $\mathrm{T}_{\text {des }}=0.33 \mathrm{~s}$

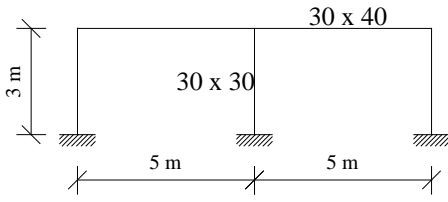

2-story structure - Tdes $_{\text {de }}=0.46 \mathrm{~s}$

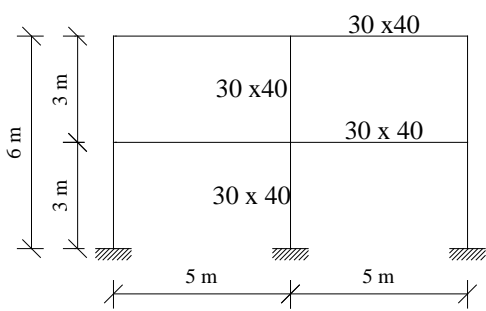

5-story structure - $\mathrm{T}_{\text {des }}=0.76 \mathrm{~s}$

3-story structure - $\mathrm{T}_{\text {des }}=0.53 \mathrm{~s}$
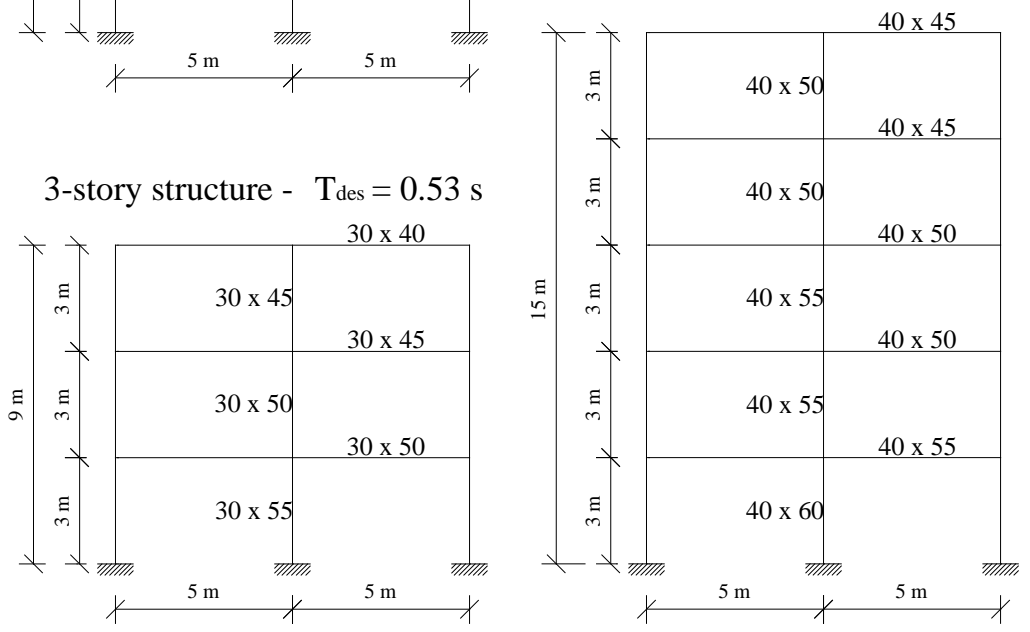

10-story structure - $\mathrm{T}_{\mathrm{des}}=1.39 \mathrm{~s}$

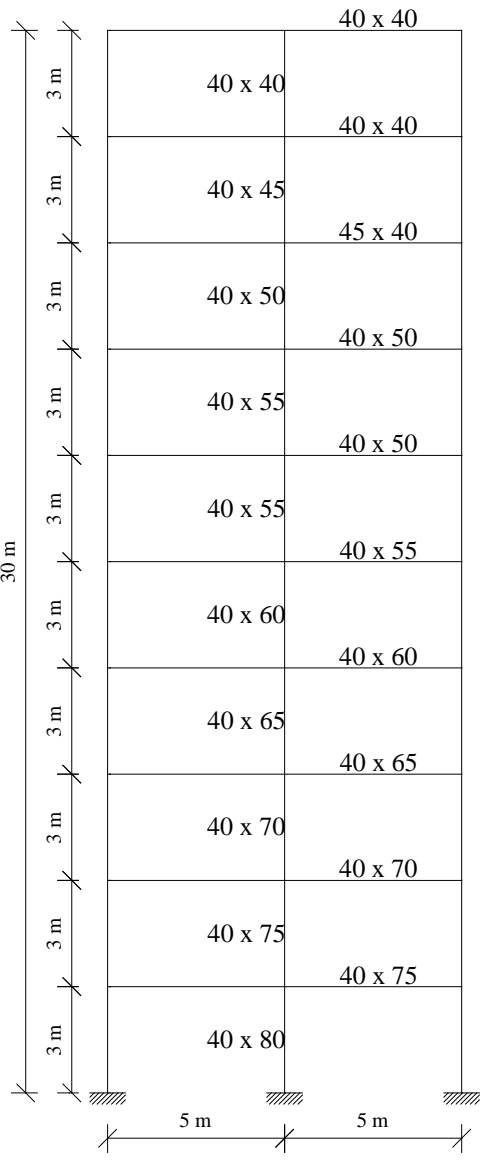

Figure 2 Lateral view of the considered building models and their design fundamental period ( $\left.T_{\text {des }}\right)$. $T_{\text {he }}$ dimensions of the cross sections are in $[\mathrm{cm}]$.

The mechanical characteristics for the steel and the concrete are calculated according to Eurocode 2 [29].

The primary elements are modeled as elastic beam-column elements in the linear model of the structures: the gross moment of inertia is considered. The concrete is modeled as an elastic material with a modulus of elasticity equal to $31476 \mathrm{~N} / \mathrm{mm}^{2}$, according to the C25/30 class concrete assumed during the design phase.

A distributed plasticity approach is selected in order to define the nonlinear model of the structures. This approach allows investigating the pre- and post-cracking behavior of the elements. The primary elements are modeled as nonlinear force-based elements [28]. For each element appropriate cross sections are defined considering the actual geometry and steel reinforcement. The cross section is divided into fibers and a stress-strain relationship is defined for each of them. Different constitutive laws are assigned to three different kinds of fibers: an unconfined concrete law is associated to the cover fibers, a confined concrete law is associated to the core fibers, a steel law is associated to the longitudinal reinforcement fibers. The stress-strain relationship for both unconfined and confined concrete are evaluated according to Mander et al. [30]. The tensile concrete strength is also considered.

The class B450C for the steel is used and a bilinear with hardening relationship is adopted.

\subsection{Ground motion records}

A set of accelerograms representative of the frequent earthquake ground motion at the considered site is defined according to the motivations included in Section 2. Eurocode 8 does not provide a formulation for the definition of the spectrum corresponding to a frequent 
earthquake. The Italian Building Code, instead, provides detailed hazard maps (a grid of more than 16,000 points) corresponding to different probabilities of exceedance in 50 years; the maps allow defining the spectrum that envelopes the uniform hazard spectrum at the site characterized by a given probability of exceedance. The maps are defined upon a probabilistic seismic hazard assessment (PSHA) of Italy performed by Stucchi et al. [31].

In order to be consistent with the spectrum adopted during the design phase, the selected point of the Italian grid exhibits a 475-y return period spectrum very close to the one assumed during the design phase. Indeed, the point, located close to the epicenter of $\left(6.9 \mathrm{M}_{\mathrm{w}}\right) 1980$ Irpinia earthquake, is characterized by a peak ground acceleration on stiff soil equal to $0.25 \mathrm{~g}$ for a $10 \%$ probability of exceedance in 50 years.

According to the Italian Building Code, a frequent earthquake is characterized by a $63 \%$ probability of exceedance in 50 years, i.e. by a 50-year return period; for the selected grid point the peak ground acceleration on stiff soil, characterized by a $63 \%$ probability of exceedance in 50 years, is equal to $0.078 \mathrm{~g}$. The 50 - year return period spectrum is shown in solid thin line in Figure 3.

A suitable set of 7 European accelerograms (Table 1) recorded on soil type B is then provided, according to the EC8 recommendations [32], matching the 50-year return period spectrum:

- the mean of zero-period spectral response acceleration values is larger than $0.094 \mathrm{~g}$, i.e. the peak ground acceleration (PGA) considering a soil type B;

- the mean elastic spectrum of the selected ground motions is larger than $90 \%$ of the target elastic response spectrum (Figure 3 ) in the range of periods between $0.2 \mathrm{~T}_{1, \mathrm{~min}}$ and $2 \mathrm{~T}_{1, \max }$, where $\mathrm{T}_{1, \min }$ and $\mathrm{T}_{1, \max }$ are, respectively, the minimum and the maximum fundamental period of the reference structures.

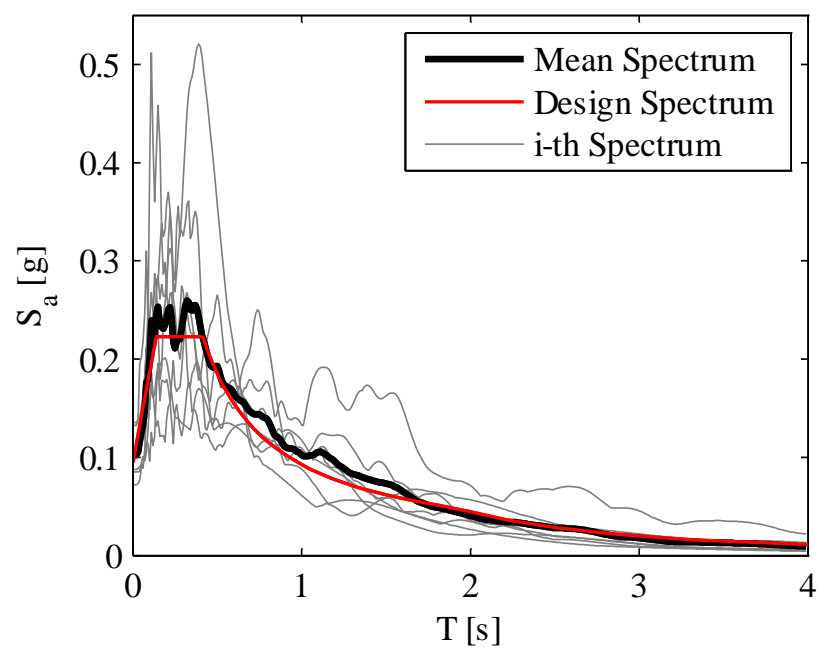

Figure 3. Comparison between design and mean natural spectrum at damage limit state. 


\begin{tabular}{|c|c|c|c|c|c|c|c|}
\hline $\begin{array}{l}\text { Waveform } \\
\text { ID }\end{array}$ & $\begin{array}{c}\text { Earthquake } \\
\text { ID }\end{array}$ & $\begin{array}{c}\text { Earthquake } \\
\text { Name }\end{array}$ & Date & $\mathbf{M}_{\mathbf{w}}$ & $\begin{array}{c}\text { Epicentral } \\
\text { Distance } \\
{[\mathrm{km}]}\end{array}$ & Direction & $\begin{array}{c}\text { PGA } \\
\text { [g] }\end{array}$ \\
\hline 761 & 292 & $\begin{array}{c}\text { Umbria } \\
\text { Marche } \\
\text { (aftershock) }\end{array}$ & 14/10/1997 & 5.6 & 21 & $\mathrm{x}$ & 0.109 \\
\hline 2017 & 664 & Drama & 09/11/1985 & 5.2 & 19 & $\mathrm{y}$ & 0.085 \\
\hline 49 & 34 & Friuli & 06/05/1976 & 6.5 & 42 & $\mathrm{y}$ & 0.088 \\
\hline 2006 & 700 & $\begin{array}{c}\text { Almiros } \\
\text { (aftershock) }\end{array}$ & $11 / 08 / 1980$ & 5.2 & 14 & $\mathrm{y}$ & 0.072 \\
\hline 231 & 108 & $\begin{array}{l}\text { Montenegro } \\
\text { (aftershock) }\end{array}$ & 24/05/1979 & 6.2 & 21 & $\mathrm{x}$ & 0.132 \\
\hline 336 & 159 & Preveza & 10/03/1981 & 5.4 & 28 & $\mathrm{x}$ & 0.136 \\
\hline 293 & 146 & $\begin{array}{l}\text { Campano } \\
\text { Lucano }\end{array}$ & 23/11/1980 & 6.9 & 33 & $\mathrm{y}$ & 0.099 \\
\hline
\end{tabular}

Table 1. Information about the earthquakes used for the dynamic analyses [33].

The selected ground motion amplitudes are not scaled. Even though the selected input motions are characterized by a significant dispersion, this phenomenon should not affect the mean response of the reference structures, as pointed out by Maddaloni et al. [32].

Vertical ground accelerations were not considered in the study. However, frame structures characterized by common, e.g. less than $6 \mathrm{~m}$, bays do not evidence significant amplification of the vertical floor accelerations.

\section{RESULTS AND DISCUSSION}

\subsection{Elastic and inelastic floor response spectra}

Dynamic analyses on the elastic and inelastic models are performed. The floor response spectrum at a given story is evaluated as the mean of the floor response spectra evaluated subjecting the structure to the 7 accelerograms reported in Table 1. A 5\% damping ratio is considered. This spectrum yields the maximum acceleration to which a nonstructural component is subjected, assuming that it is schematized as a single degree of freedom with a natural period T. The floor response spectra resulting from elastic and inelastic models are plotted and compared in Figure 4.

Both in elastic and inelastic models, peaks are exhibited in the floor spectra for a period close to the natural periods of the primary structure. This phenomenon is caused by the filtering action of the primary structure that modifies the frequency content of the base input at the different stories; the floor motion is characterized by a large frequency content for frequencies close to the natural frequencies of the structure. The nonstructural component at a given floor, which is characterized by a natural period close to the structural one, is subjected to the large accelerations denoted by the peak in the floor spectra.

However, for inelastic models the peaks do not correspond to natural periods because the primary elements, subjected both to vertical loads and horizontal seismic action, exhibit a stiffness reduction due to the cracking, leading to the natural period elongation phenomenon. The influence of higher modes is more evident for tall buildings, whose floor spectral accelerations, associated to the higher modes, are greater than the ones corresponding to the first mode. This phenomenon is more evident for inelastic models, in which the reduction of the floor spectral ordinates mainly involves the first mode peak, whereas the peaks corresponding to the higher modes are only slightly reduced. It is interesting to note that the reduction of the spectral ordinates is significant despite the structural elements are not yielded; the nonlinearity due to the cracking of the elements could be significantly beneficial 
in terms of the seismic demand on nonstructural components, especially for long-period nonstructural components in tall structures.

It should be noted that the frequent seismic action considered in this study produces a demand on nonstructural components that is much smaller than the demand caused by the rare seismic action considered in [23] on the same reference structures. Considering inelastic models, the seismic demand on nonstructural component due to a frequent seismic action does not exceed $0.9 \mathrm{~g}$, whereas the demand due to rare earthquakes may be close to $3 \mathrm{~g}$ [23]. 


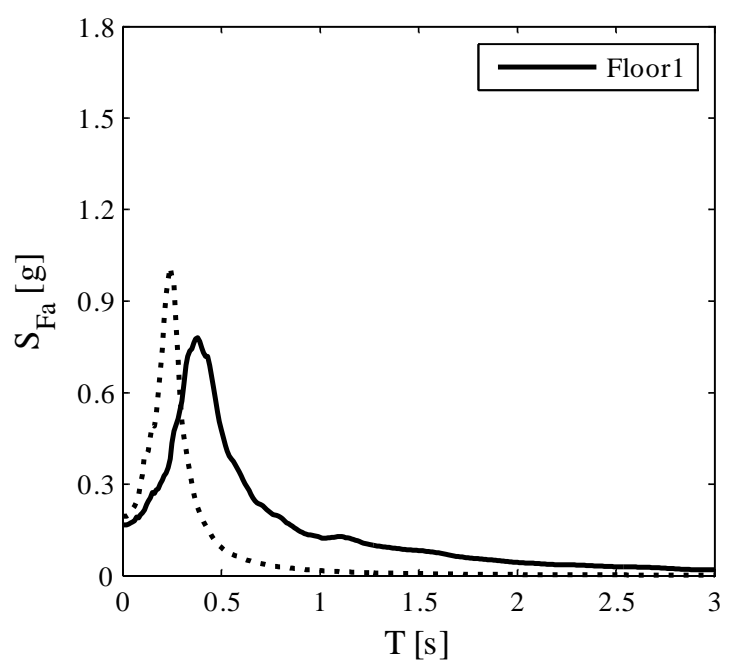

(a)

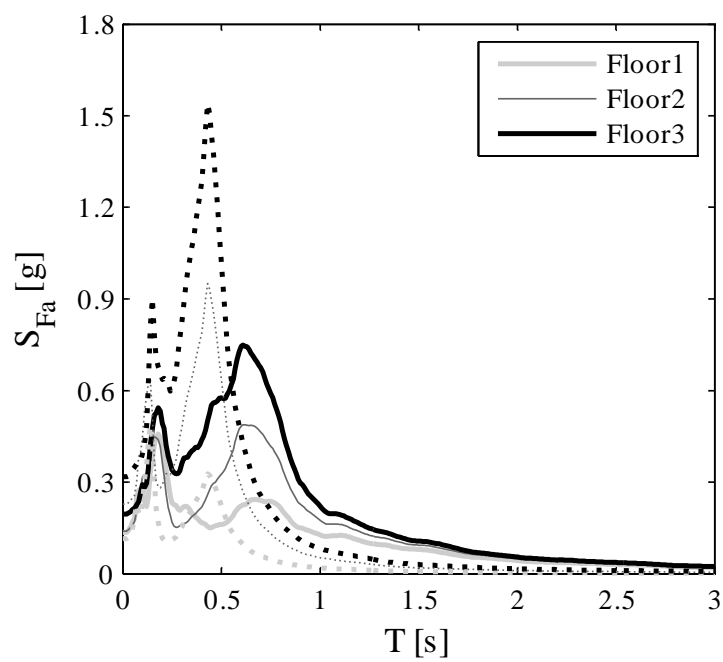

(c)

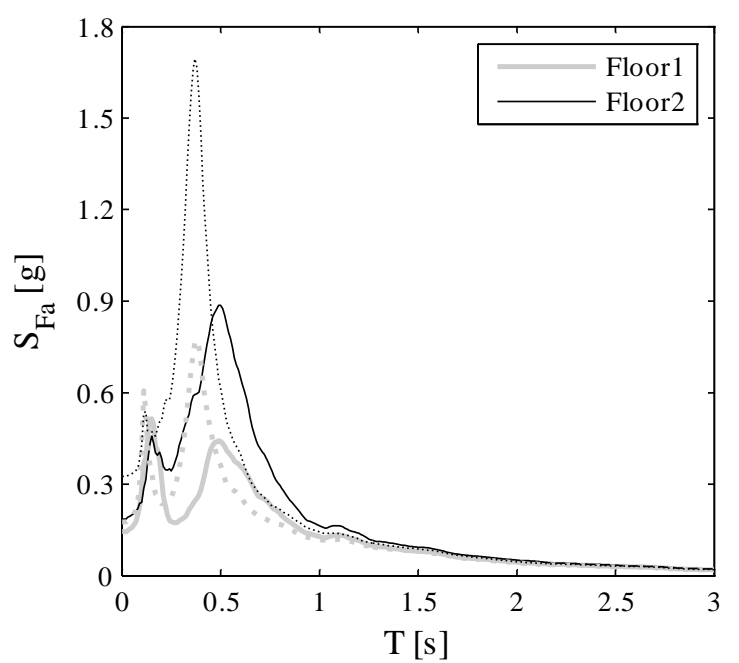

(b)

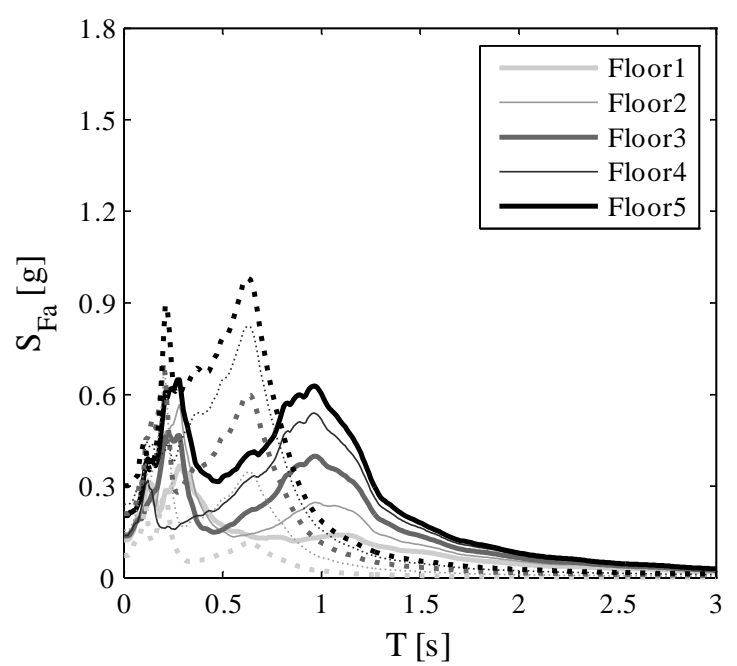

(d)

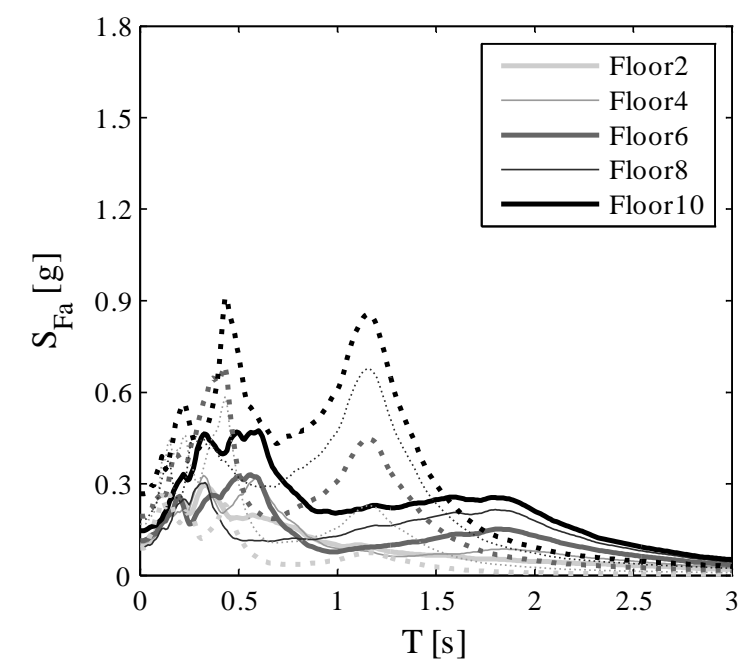

(e)

Figure 4. Floor response spectra in elastic (dotted lines) and inelastic (solid lines) models for (a) 1-story structure, (b) 2-story structure, (c) 3-story structure, (d) 5-story structure and (e) 10-story structure. 


\subsection{Floor amplification evaluation}

The trends of the ratio between the peak floor acceleration (PFA) and the peak ground acceleration (PGA) are plotted in Figure 5, in order to study the acceleration amplification at the different story levels.

Both elastic and inelastic models show almost linear trends, excepting the 10-story structure, in which the shape of the PFA/PGA trend is influenced by the second mode displacement shape at the top stories. A reduction of the PFA/PGA ratio is exhibited in the inelastic models with respect to the elastic ones, due to the cracking of the primary elements; however, at lower stories of the tallest buildings, i.e. 5- and 10-story structures, a slight increase is recorded. This latter phenomenon could be caused by the great influence that higher modes have when structural nonlinearity, i.e. cracking, occurs [34, 35].

The PFA/PGA trends are compared to the provisions included in ASCE 7 [36] and EC8 that define a linear trend that goes from 1 at the base of the structure to 2.5 and 3 at the top for EC8 and ASCE 7 respectively. Both the EC8 and ASCE 7 envelopes overestimate the numerical outcomes; it is noted that inelastic models are considered, since they, through the inclusion of the cracking in the elements, better predict the actual behavior of the structures. An envelope that goes from 1 at the base of the structure to 2 at the top would better fit the results.

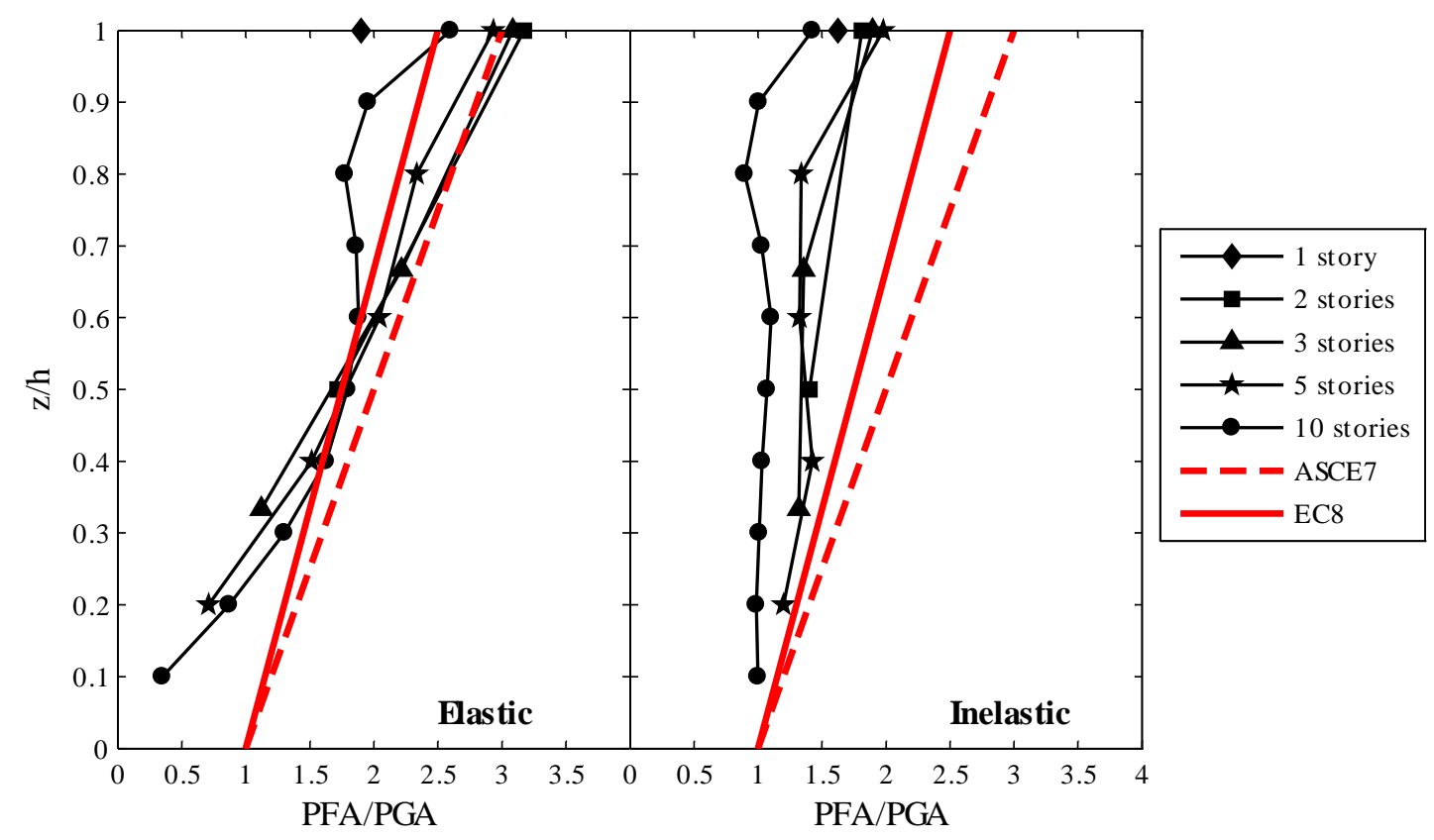

Figure 5. Ratio between peak floor acceleration (PFA) and peak ground acceleration (PGA), versus the relative height (z/h) compared to the provisions included in ASCE7 and EC8.

\subsection{Component amplification evaluation}

The trends of the ratio $a_{p}$ between the maximum floor spectrum acceleration $\left(S_{F a, m a x}\right)$ and the PFA with respect to the relative height are shown in Figure 6, in order to study the component acceleration magnification of the floor accelerations. The outcomes corresponding to the elastic and inelastic models are compared: only slight differences are exhibited. The $\mathrm{a}_{\mathrm{p}}$ ratio ranges from 3.0 to 5.2 in elastic models whereas it ranges from 2.6 to 4.8 in inelastic models. The component acceleration magnifications in tall buildings are generally smaller than the ones in short structures.

The trends are compared to the provisions included in ASCE7 and EC8, that define a trend that goes from 2.5 at the base of the structure to 2.5 and 2.2 at the top for ASCE7 and EC8 
respectively (Figure 6). Hence, a noteworthy underestimation of the $\mathrm{a}_{\mathrm{p}}$ values in the current building codes is clearly evidenced, as shown in Medina et al. [22].

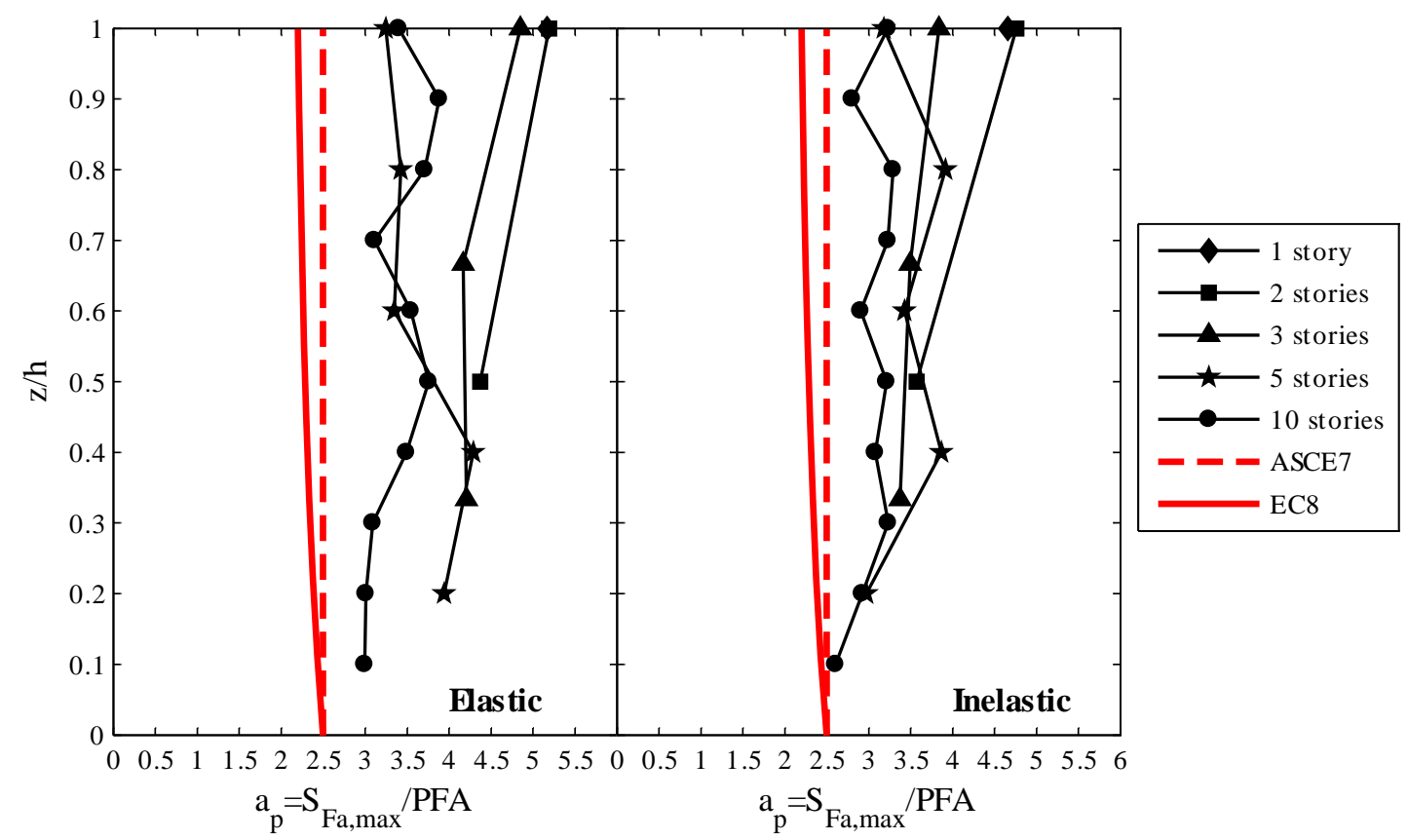

Figure 6. Floor acceleration magnification on nonstructural components versus the relative height (z/h) compared to the provisions included in ASCE7 and EC8.

It should be noted that the fundamental period of a nonstructural component can increase in case either itself or its connection/anchorage exhibits a nonlinear behavior. This phenomenon induces a different acceleration demand on the component, which results in a different $a_{p}$ value.

\subsection{Comparison with EC8 formula and limitations}

Eurocode 8 [18] provides that the floor spectral acceleration, i.e. the maximum acceleration on a SDOF nonstructural component, is evaluated as:

$$
S_{F a, E C 8}(T)=\alpha \cdot S \cdot\left[\frac{3 \cdot(1+z / H)}{1+\left(1-T / T_{1}\right)^{2}}-0.5\right] \cdot g \geq \alpha \cdot S \cdot g
$$

where:

- $\alpha$ is the ratio between the peak ground acceleration on stiff soil and the gravity acceleration;

- $\quad \mathrm{S}$ is a soil amplification factor;

- $\mathrm{z} / \mathrm{H}$ is the relative structural height at which the component is located;

- $\mathrm{T}$ is the nonstructural component period;

- $\mathrm{T}_{1}$ is the fundamental period of the primary structure, assumed during the design phase.

The Eurocode 8 floor response spectrum could be then compared to the floor spectra resulting from the analyses, assuming in the formulation (1) a peak ground acceleration on stiff soil equal to $0.078 \mathrm{~g}$, i.e. the 50 -year return period peak ground acceleration. In Figure 7 the floor spectra are compared to Eurocode 8 floor spectra for the different structures considered in this study. In order to take into account the realistic behavior of the primary structures, floor spectra in inelastic models are considered. 
This comparison underlines that Eurocode 8 typically underestimates the acceleration demand on nonstructural component for a wide range of periods, especially for periods close to the structural natural periods. Eurocode floor spectra give a good approximation, typically safesided, of the floor spectra for period sufficiently larger than the fundamental period of the structure. 


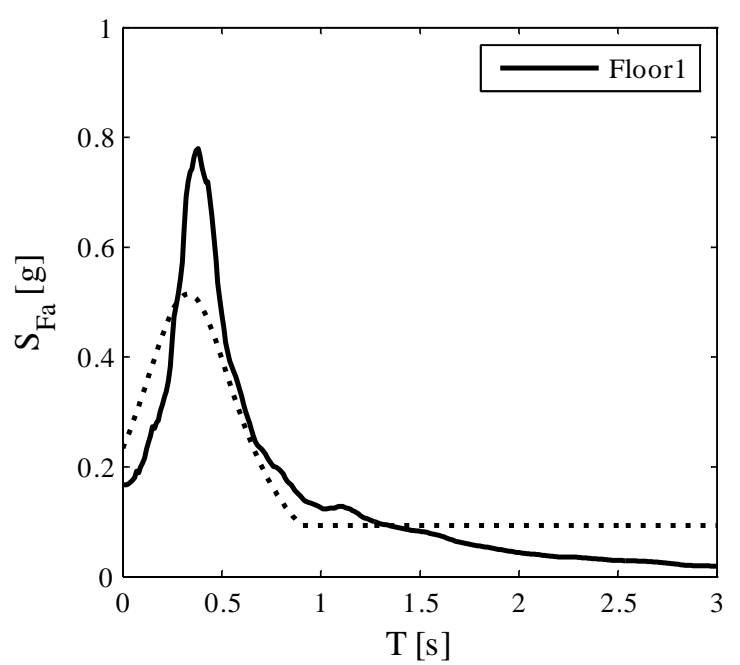

(a)

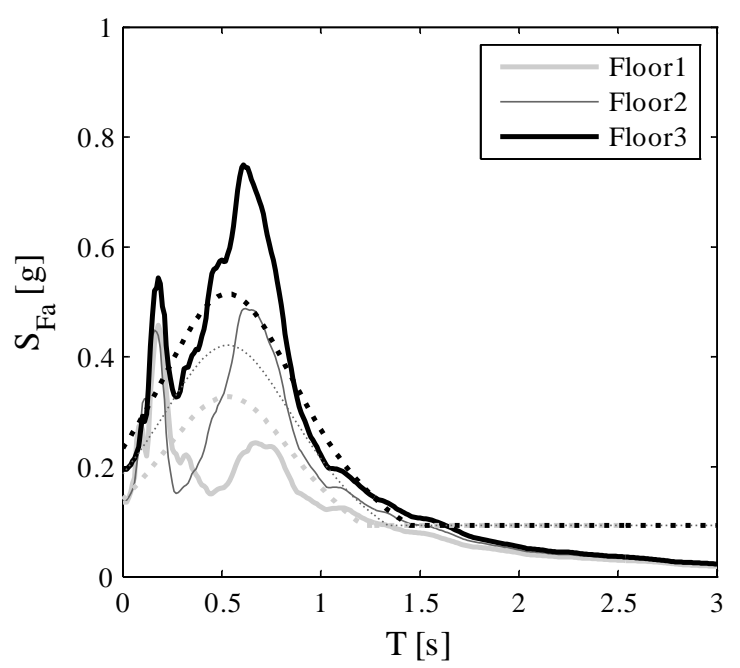

(c)

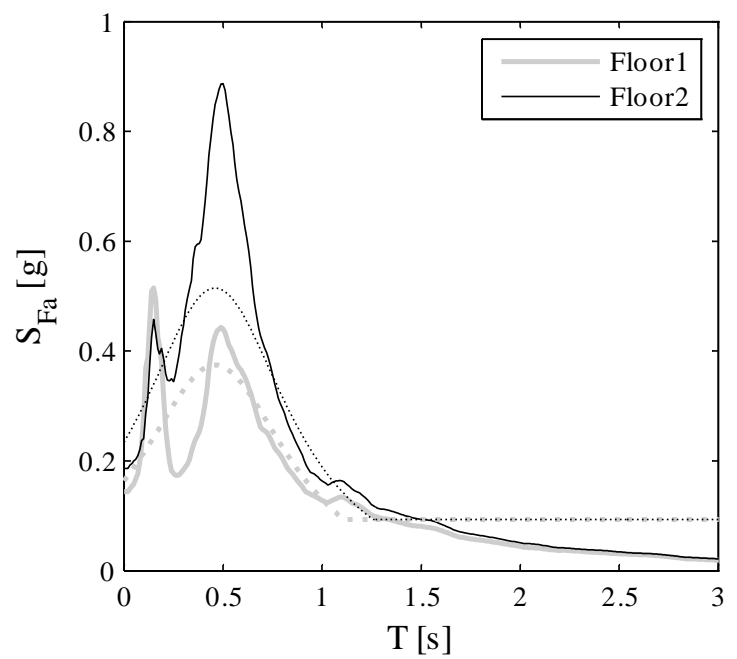

(b)

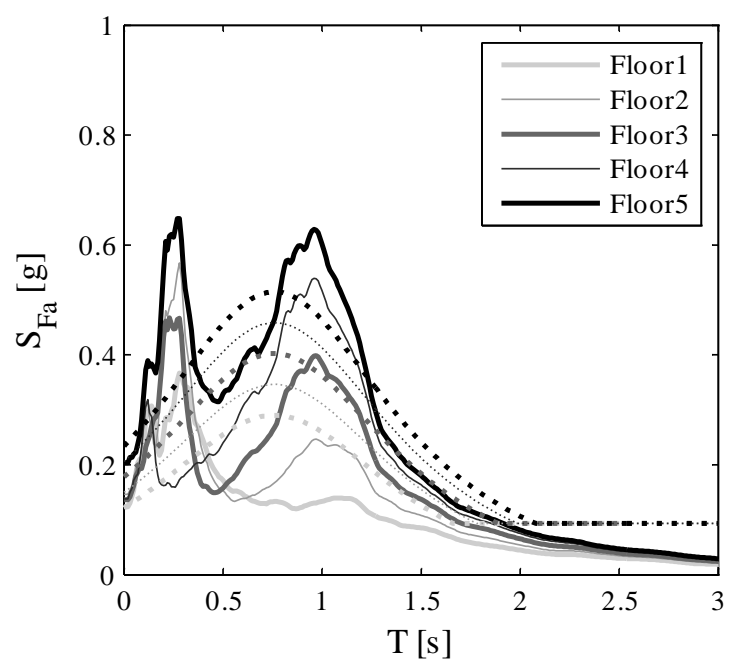

(d)

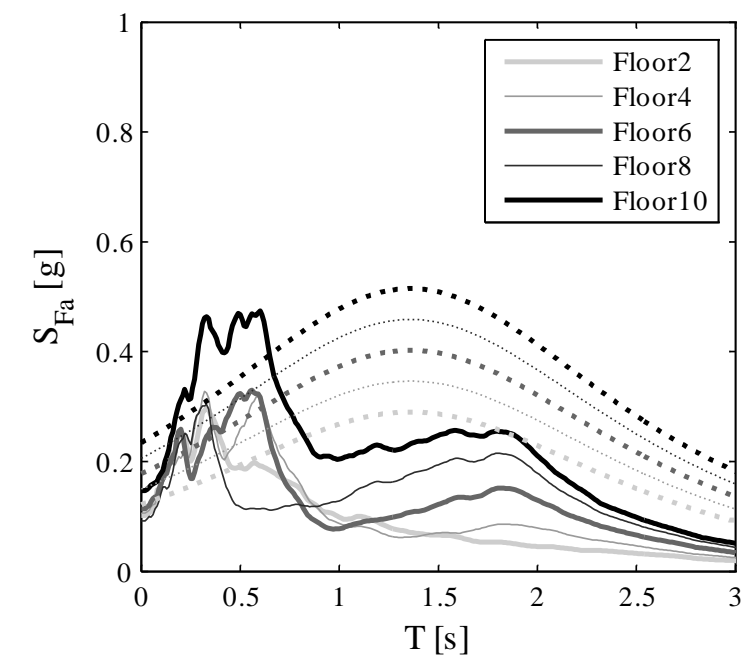

(e)

Figure 7. Floor response spectra (solid lines) on inelastic models compared to Eurocode 8 floor spectra (dashed lines) for the (a) 1-story, (b) 2-story, (c) 3-story, (d) 5-story and (e) 10-story structures. 
They also give a good approximation of the period ( $\mathrm{T}_{\mathrm{des}}$ in Figure 2$)$ at which the maximum floor spectral acceleration occurs; this is caused by the assumption of halved inertia during the design phase, in order to take into account the effects of cracking.

Higher mode effects are not considered in the formulation (1): a significant underestimation is recorded in the range of periods close to the higher mode periods of vibration. The effective floor spectrum acceleration can be significantly underestimated, especially for tall buildings, i.e. the 5- and the 10-story structures, in which the higher modes are predominant. An urgent need to include higher modes in the code formulation is clearly evidenced.

\subsection{Definition of a code formula}

The previous sections clearly evidenced the inadequacy of the Eurocode provisions for the evaluation of the seismic demand on acceleration-sensitive nonstructural components. The main issues of the EC8 formulation can be summarized in: (a) the slight overestimation of the peak floor acceleration (see Section 4.2), (b) the significant underestimation of the component acceleration magnification at a given floor (see Section 4.3), (c) the non-inclusion of the higher mode effects in the formulation, that leads to a significant underestimation of the floor spectral acceleration for small periods (see Section 4.4). However, the shape of the Eurocode floor spectrum is found to suitably catch the shape of typical floor response spectra.

In this Section a novel formulation is proposed (Figure 8): it is based on the Eurocode formulation and on some suggestions included in [16]. A formula similar to the one already included in the Eurocode is defined, both for the sake of simplicity and in order to facilitate the implementation in future building codes.

- A three-branch floor response spectrum is defined (branches from no. 1 to no. 3 in Figure 8). The branches no. 1 and no. 3 have a shape similar to the Eurocode 8 floor spectrum. The definition of the flat branch no. 2 allows considering the peaks corresponding to both the first and the higher modes of the primary structure; it is also capable to include the uncertainty in the evaluation of the structural periods.

- The formula included in EC8 is slightly modified in order to directly distinguish the different terms, i.e. ground acceleration, floor amplification and component amplification, that influence the definition of the floor response spectrum $\left(\mathrm{S}_{\mathrm{Fa}}\right)$.

- The PFA over PGA ratio trend is modified according to the evidence described in the Section 4.2. The proposed ratio trend goes from 1 at the base of the structure to 2 at its top.

- The amplification factor $a_{p}$ is increased up to 5 for short buildings and is reduced for tall ones (Table 2), according to the analytical results (Figure 6). 


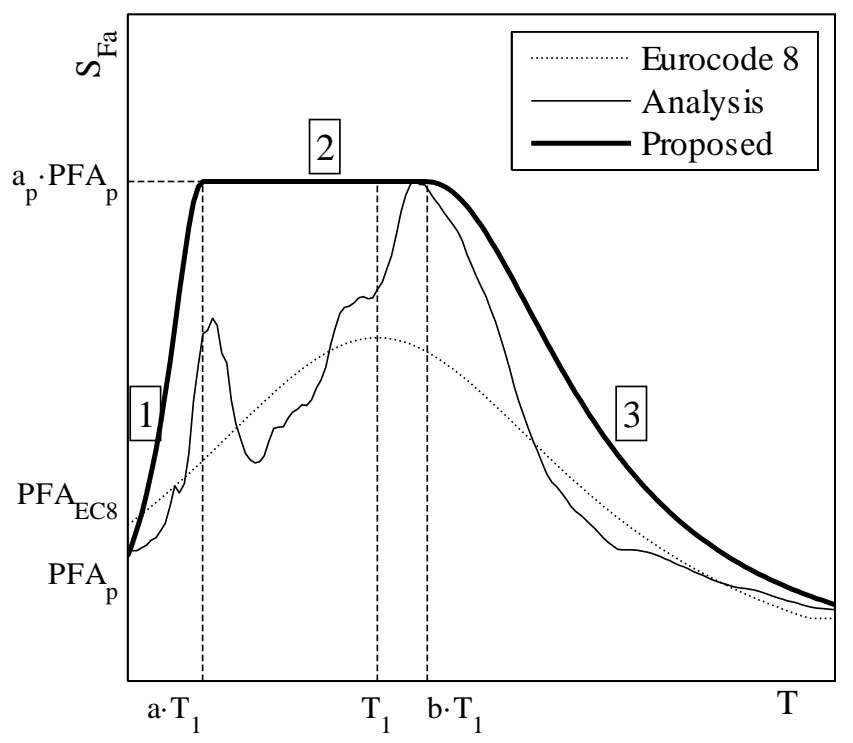

Figure 8. Proposed floor spectral shape compared to the Eurocode 8 floor spectral shape and to a typical analytical floor spectrum.

The proposed response spectra is defined according to the following formulation:

$$
S_{\text {Fa, proposed }}(T)=\left\{\begin{array}{lr}
\alpha \cdot S \cdot g \cdot(1+z / H) \cdot\left[\frac{a_{p}}{1+\left(a_{p}-1\right)\left(1-T / a \cdot T_{1}\right)^{2}}\right] \geq \alpha \cdot S \cdot g & \text { for } T<a \cdot T_{1} \\
\alpha \cdot S \cdot g \cdot(1+z / H) \cdot a_{p} & \text { for } a \cdot T_{1}<T<b \cdot T_{1} \\
\alpha \cdot S \cdot g \cdot(1+z / H) \cdot\left[\frac{a_{p}}{1+\left(a_{p}-1\right)\left(1-T / b \cdot T_{1}\right)^{2}}\right] \geq \alpha \cdot S \cdot g & \text { for } T>b \cdot T_{1}
\end{array}\right.
$$

The parameters $\mathrm{a}, \mathrm{b}$ and $\mathrm{a}_{\mathrm{p}}$ are defined according to the fundamental period of the structure $\mathrm{T}_{1}$ as reported in Table 2. They are based on the indications included in [16] and they are then calibrated in order to ensure a good matching between the analytical floor response spectra and the proposed floor spectra. The other parameters are the same as in Eurocode formula (1).

\begin{tabular}{cccc}
\hline & $\mathrm{a}[-]$ & $\mathrm{b}[-]$ & $\mathrm{a}_{\mathrm{p}}[-]$ \\
\hline $\mathrm{T}_{1}<0.5 \mathrm{sec}$ & 0.8 & 1.4 & 5.0 \\
\hline $0.5 \mathrm{sec}<\mathrm{T}_{1}<1.0 \mathrm{sec}$ & 0.3 & 1.2 & 4.0 \\
\hline $\mathrm{T}_{1}>1.0 \mathrm{sec}$ & 0.3 & 1.0 & 2.5 \\
\hline
\end{tabular}

Table 2. Values of the parameters of the proposed formulation for different ranges of structural periods.

In Figure 9 the floor spectra are evaluated according to the proposed formulation (2) and compared to the analytical floor spectra evaluated on the inelastic models. The proposed floor spectra are typically safe-sided with respect to the analytical results. They are also capable to include the peaks related to the structural higher modes; the reduction of the seismic demand on very flexible nonstructural components is also caught. 


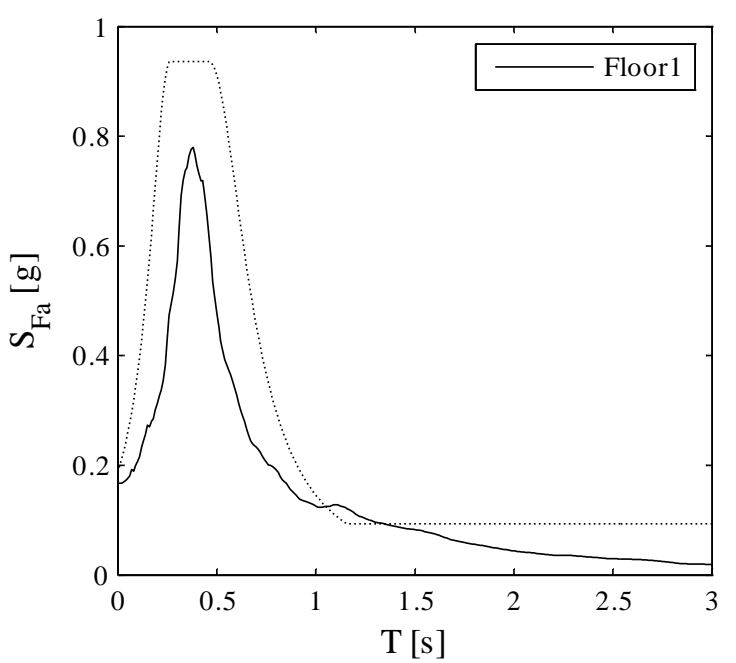

(a)

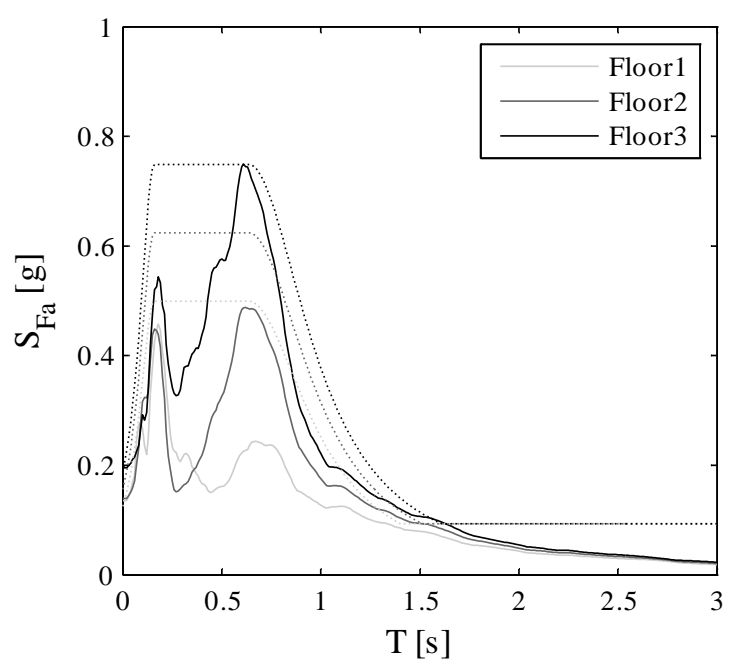

(c)

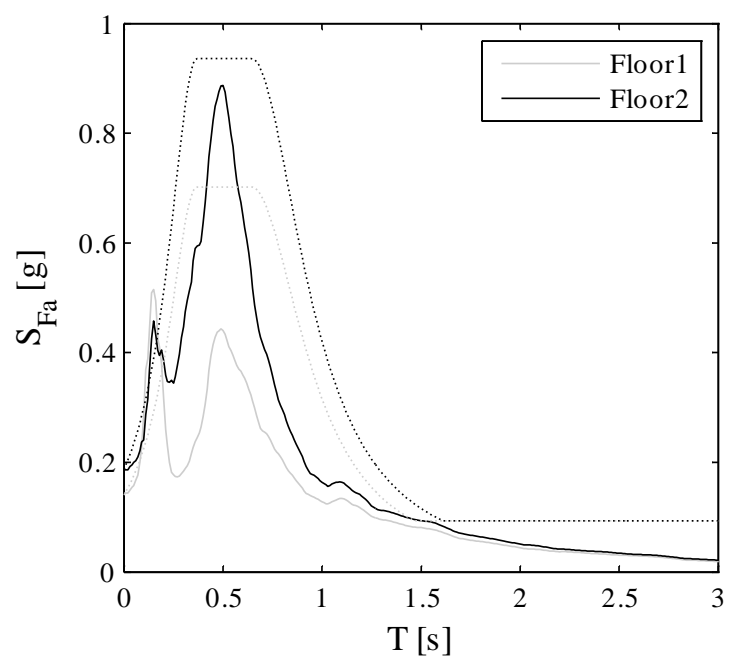

(b)

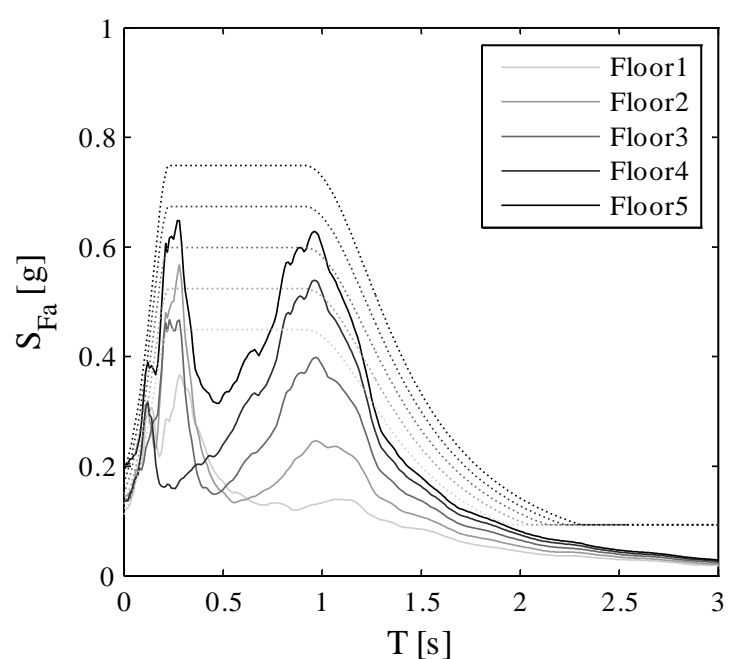

(d)

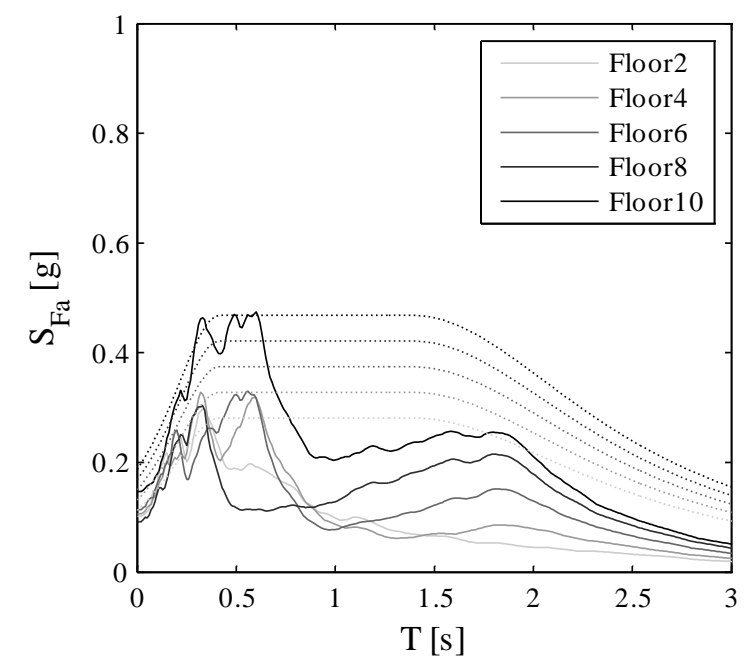

(e)

Figure 9 Floor response spectra (solid lines) on inelastic models compared to the proposed floor spectra according to the formulation (2) (dashed lines) for the (a) 1-story, (b) 2-story, (c) 3-story, (d) 5-story and (e) 10-story structures 
The proposed formulation yields conservative floor spectral accelerations for a wide range of periods, especially for periods close to the fundamental period; however, this overestimation could cover the uncertainty in the estimation of the structural period due to, for instance, the presence of stiff infill walls and partition walls [37], as well as the uncertainty in the estimation of the nonstructural component period during the design phase.

The definition of such a formulation requires that the designer knows the fundamental period of the considered nonstructural component. Since it is not reasonable that a designer should evaluate the fundamental periods of nonstructural components, the manufacturer should include this value in its technical data sheet; some experimental activities aimed at the evaluation of the natural frequency of nonstructural components can be also conducted, as for instance [3, 38].

\section{CONCLUSIONS}

Floor response spectra are evaluated through time-history analyses on a set of five RC frame structures with different number of stories. The floor spectra are evaluated according to a set of accelerograms compatible to a design frequent seismic input. The investigation of floor response spectra induced by frequent earthquakes is motivated following a detailed analysis of the limit states definition in the actual European and Italian building codes.

Both elastic and inelastic models of the reference structures are considered. A period elongation phenomenon is clearly evidenced in floor spectra of the inelastic models, which is mainly caused by the cracking of the primary elements. The nonlinearity due to the cracking of the elements also induces a reduction of the floor spectral ordinates; the reduction of the floor spectral ordinates mainly involves the floor spectrum peak corresponding to the first mode, whereas the peaks corresponding to the higher modes are only slightly reduced. For tall buildings, the floor spectral accelerations associated to the higher modes are greater than those corresponding to the first mode.

The peak floor acceleration shows an almost linear trend with the structural relative height. The predictions included both in EC8 and ASCE 7 are conservative, i.e. they provide larger values of peak floor acceleration compared to the accelerations that result from the analyses. The peak component acceleration, i.e. the maximum floor spectral acceleration value at a given story, normalized to the peak floor acceleration, exhibits an almost constant trend with the structural relative height. Moreover, the taller the structure is, the smaller the component amplification factor becomes. A significant unsafe-sided prediction of both EC8 and ASCE 7 provisions is demonstrated.

The comparison of the floor spectra of inelastic models with the EC8 provisions clearly underlines that Eurocode 8 typically underestimates the acceleration demand on nonstructural component for a wide range of periods. Eurocode floor spectra give a good approximation, typically safe-sided, of the floor spectra for periods sufficiently larger than the fundamental period of the structure. A significant underestimation is recorded in the range of periods close to the higher mode periods of vibration of the reference structures.

A novel formulation is then proposed, based on the Eurocode current formulation, for an implementation in the future building codes. The proposed formulation is able to envelope the floor spectral peaks due to the higher modes. Moreover, it yields conservative floor spectral acceleration for a wide range of periods, especially for periods close to the fundamental period. However, such an overestimation could cover the uncertainty in the estimation of the structural and the nonstructural component periods during the design phase.

It should be underlined that the above presented results and conclusions are related and limited to a set of frame reinforced concrete structures designed according to Eurocode 8. A larger set of structures, characterized by different materials and structural typologies, should be considered in a future study in order to validate the proposed formulation. 


\section{ACKNOWLEDGMENTS}

This research study has been partially funded by the Italian Department of Civil Protection in the framework of the national project DPC-ReLUIS 2014 RS8.

The authors also acknowledge Eng. Maddalena Cimmino for the execution of numerical analyses. Authors thank Ms. Raffaelina Divano, English language expert, for the paper proofreading.

\section{REFERENCES}

[1] Villaverde R. Seismic design of secondary structures: State of the art. Journal of Structural Engineering-Asce 1997; 123 (8): 1011-1019. DOI:10.1061/(Asce)07339445(1997)123:8(1011).

[2] Taghavi S, Miranda E. Response assessment of nonstructural building elements, PEER report 2003/05. College of Engineering, University of California Berkeley, USA, 2003.

[3] Magliulo G, Petrone C, Capozzi V, Maddaloni G, Lopez P, Manfredi G. Seismic performance evaluation of plasterboard partitions via shake table tests. Bulletin of Earthquake Engineering 2014; 12 (4): 1657-1677. DOI:10.1007/s10518-013-9567-8.

[4] Magliulo G, Ercolino M, Petrone C, Coppola O, Manfredi G. The Emilia Earthquake: the Seismic Performance of Precast Reinforced Concrete Buildings. Earthquake Spectra 2014; 30 (2): 891-912. DOI:10.1193/091012EQS285M.

[5] Earthquake Engineering Research Institute (EERI). Nonstructural Issues of Seismic Design and Construction, Publication 84-04. Berkeley, CA, USA, 1984.

[6] Magliulo G, Pentangelo V, Maddaloni G, Capozzi V, Petrone C, Lopez P, Talamonti R, Manfredi G. Shake table tests for seismic assessment of suspended continuous ceilings. Bulletin of Earthquake Engineering 2012; 10 (6): 1819-1832. DOI:10.1007/s10518-012-9383-6.

[7] Magliulo G, Petrone C, Capozzi V, Maddaloni G, Lopez P, Talamonti R, Manfredi G. Shake Table Tests on Infill Plasterboard Partitions. The Open Construction and Building Technology Journal 2012; 6 (Suppl 1-M10): 155-163. DOI:10.2174/1874836801206010155.

[8] Lin J, Mahin S. Seismic Response of Light Subsystems on Inelastic Structures. $\begin{array}{lllll}\text { Journal of Structural Engineering 1985; } 111 & \text { (2): 400-417. }\end{array}$ DOI:10.1061/(ASCE)0733-9445(1985)111:2(400).

[9] Sewell RT, Cornell CA, Toro GR, McGuire RK. A study of factors influencing floor response spectra in nonlinear multi-degree-of-freedom structures. Report No. 82. The John A. Blume Earthquake Engineering Center, Stanford University, Stanford, California, 1988.

[10] Sewell RT, Cornell CA, Toro GR, McGuire RK, Kassawara RP, Sing A. Factors influencing equipment response in linear and nonlinear structures. Lausanne, Switzerland, 1989.

[11] Politopoulos I, Feau C. Some aspects of floor spectra of 1DOF nonlinear primary structures. Earthquake Engineering \& Structural Dynamics 2007; 36 (8): 975-993. DOI:10.1002/eqe.664.

[12] Politopoulos I. Floor Spectra of MDOF Nonlinear Structures. Journal of Earthquake Engineering 2010; 14 (5): 726-742. DOI:10.1080/13632460903427826.

[13] Rodriguez ME, Restrepo JI, Carr AJ. Earthquake-induced floor horizontal accelerations in buildings. Earthquake Engineering and Structural Dynamics 2002; 31 (3): 693-718. DOI:10.1002/eqe.149. 
[14] Singh M, Moreschi L, Suárez L, Matheu E. Seismic Design Forces. II: Flexible Nonstructural Components. Journal of Structural Engineering 2006; 132 (10): 15331542. DOI:10.1061/(ASCE)0733-9445(2006)132:10(1533).

[15] Singh M, Moreschi L, Suárez L, Matheu E. Seismic Design Forces. I: Rigid Nonstructural Components. Journal of Structural Engineering 2006; 132 (10): 15241532. DOI:10.1061/(ASCE)0733-9445(2006)132:10(1524).

[16] Fathali S, Lizundia B. Evaluation of current seismic design equations for nonstructural components in tall buildings using strong motion records. The Structural Design of Tall and Special Buildings 2011; 20 30-46. DOI:10.1002/tal.736.

[17] Sullivan TJ, Calvi PM, Nascimbene R. Towards improved floor spectra estimates for seismic design. Earthquakes and Structures 2013; 4 (1): 109-132. DOI:10.12989/eas.2013.4.1.109.

[18] CEN. Eurocode 8: design of structures for earthquake resistance - Part 1: general rules, seismic actions and rules for buildings. EN 1998-1. Brussels, Belgium., 2004.

[19] Consiglio Superiore dei Lavori Pubblici. Decreto Ministeriale del 14/01/2008, Approvazione delle nuove norme tecniche per le costruzioni. G.U. n. 29 del 4/2/2008 (in Italian), 2008.

[20] Structural Engineers Association of California (SEAOC). Vision 2000 - A Framework for Performance-based Design. California Office of Emergency Services, 1995.

[21] Gatscher JA, Bachman R. Elements of 2012 IBC / ASCE 7-10 Nonstructural Seismic Provisions: Bridging the Implementation Gap. Lisboa, Portugal, 2012.

[22] Medina RA, Sankaranarayanan R, Kingston KM. Floor response spectra for light components mounted on regular moment-resisting frame structures. Engineering Structures 2006; 28 (14): 1927-1940. DOI:10.1016/j.engstruct.2006.03.022.

[23] Petrone C, Magliulo G, Manfredi G. Floor response spectra in RC frame structures designed according to Eurocode 8. Journal of Earthquake Engineering 2014; (submitted for publication)

[24] D'Ambrisi A, Mezzi M. Probabilistic estimate of seismic response design values of RC frames. Earthquake Engineering \& Structural Dynamics 2009; 38 (15): 17091727. DOI:10.1002/eqe.925.

[25] D'Ambrisi A, Mezzi M. A probabilistic approach for estimating the seismic response of elasto-plastic SDOF systems. Earthquake Engineering \& Structural Dynamics 2005; 34 (14): 1737-1753. DOI:10.1002/eqe.509.

[26] Polese M, Verderame GM, Mariniello C, Iervolino I, Manfredi G. Vulnerability Analysis for Gravity Load Designed RC Buildings in Naples - Italy. Journal of

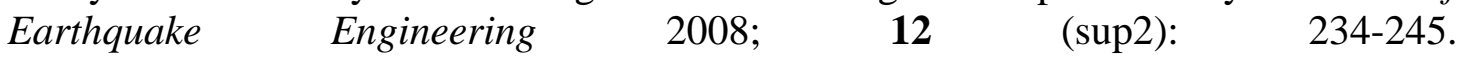
DOI:10.1080/13632460802014147.

[27] Masi A. Seismic Vulnerability Assessment of Gravity Load Designed R/C Frames. Bulletin of Earthquake Engineering 2003; $1 \quad$ (3): 371-395. DOI:10.1023/B:BEEE.0000021426.31223.60.

[28] McKenna F, Fenves GL. OpenSees Manual http://opensees.berkeley.edu. Pacific Earthquake Engineering Research Center, Berkeley, California.: 2013.

[29] CEN. Eurocode 2: Design of concrete structures - Part 1-1: General rules and rules for buildings. EN 1992-1-1. Brussels, Belgium, 2004.

[30] Mander J, Priestley M, Park R. Theoretical Stress-Strain Model for Confined Concrete. Journal of Structural Engineering 1988; 114 (8): 1804-1826. DOI:10.1061/(ASCE)0733-9445(1988)114:8(1804).

[31] Stucchi M, Meletti C, Montaldo V, Crowley H, Calvi GM, Boschi E. Seismic Hazard Assessment (2003-2009) for the Italian Building Code. Bulletin of the Seismological Society of America 2011; 101 (4): 1885-1911. DOI:10.1785/0120100130. 
[32] Maddaloni G, Magliulo G, Cosenza E. Effect of the seismic input on non-linear response of R/C building structures. Advances in Structural Engineering 2012; 15 (10): 1861-1877.

[33] Ambraseys N, Smit P, Sigbjornsson R, Suhadolc P, Margaris B. Internet-Site for European Strong-Motion Data. European Commission, Research-Directorate General, Environment and Climate Programme, 2002.

[34] Fischinger M, Ercolino M, Kramar M, Petrone C, Isakovic T. Inelastic seismic shear in multi-storey cantilever columns. 25-28 May 2011. Corfu, Greece, 2011.

[35] Rejec K, Isaković T, Fischinger M. Seismic shear force magnification in RC cantilever structural walls, designed according to Eurocode 8. Bulletin of Earthquake Engineering 2012; 10 (2): 567-586. DOI:10.1007/s10518-011-9294-y.

[36] American Society of Civil Engineers. ASCE/SEI 7-10: Minimum Design Loads for Buildings and Other Structures. Reston, Virginia, US, 2010.

[37] Petrone C, Magliulo G, Manfredi G. Shake table tests for the seismic assessment of hollow brick internal partitions. Engineering Structures 2014; 72 203-214. DOI:10.1016/j.engstruct.2014.04.044.

[38] Hutchinson TC, Chaudhuri SR. Bench-shelf system dynamic characteristics and their effects on equipment and contents. Earthquake Engineering \& Structural Dynamics 2006; 35 (13): 1631-1651. DOI:10.1002/Eqe.596. 